\section{BMJ Paediatrics Open}

\title{
Social stigmatisation in late identified patients with disorders of sex development in Indonesia
}

Annastasia Ediati, ${ }^{1,2}$ A Zulfa Juniarto, ${ }^{2,3}$ Erwin Birnie, ${ }^{4}$ Jolanda Okkerse, ${ }^{5}$ Amy Wisniewski, ${ }^{6}$ Stenvert Drop, ${ }^{7}$ Sultana M H Faradz, ${ }^{2}$ Arianne Dessens ${ }^{5}$

To cite: Ediati A, Juniarto AZ, Birnie E, et al. Social stigmatisation in late identified patients with disorders of sex development in Indonesia. BMJ Paediatrics Open 2017;1:e000130. doi:10.1136/ bmjpo-2017-000130

Received 30 May 2017 Revised 21 August 2017 Accepted 22 August 2017

\section{(a) CrossMark}

${ }^{1}$ Faculty of Psychology, Diponegoro University, Semarang, Indonesia ${ }^{2}$ Center for Biomedical Research, Faculty of Medicine, Diponegoro University, Semarang, Jawa Tengah, Indonesia

${ }^{3}$ Dr. Kariadi Hospital, Semarang, Indonesia

${ }^{4}$ Department of Genetics, University Medical Center Groningen, University of Groningen, Groningen, The Netherlands

${ }^{5}$ Department of Child and Adolescent Psychiatry and Psychology, Erasmus MC Sophia, Rotterdam, The Netherlands

${ }^{6}$ Genitourinary Institute, Cook Children's Hospital, Fort Worth, Texas, USA

${ }^{7}$ Department of Pediatrics, Erasmus MC Sophia, Rotterdam, The Netherlands

Correspondence to Dr Arianne Dessens; a.b. dessens@erasmusmc.nl

\section{ABSTRACT}

Objectives To assess social stigmatisation related to atypical appearance of the body, including, but not limited to the external genitalia, among Indonesian patients with a disorder of sex development (DSD). Until recently, diagnostic evaluation, information about the underlying causes of DSD and treatment options were sparsely available for these patients.

Methods Eighty-one parents of children and adolescents with DSD (aged 6-17 years) and 34 adult patients with DSD (aged 18-41 years) completed the Social Stigmatisation Scale towards DSD, an instrument developed to assesses the frequency of stigmatisation and the level of stress associated with these experiences. Open-ended questions investigated detailed information on stigmatisation as well as parents' and patients' emotional and behavioural reactions to these experiences. Differences in stigmatisation were explored across sex of rearing, gender change history, treatment status and DSD characteristics that could be easily identified by others (e.g., masculinisation of the body in women).

Results Social stigmatisation was reported by patients with atypical appearance of their genitalia, atypical appearance of their body aside from their genitals, among those who displayed cross-gender behaviour and those who changed gender. Among participants reared as women and among children and adolescents who changed gender, social stigmatisation was associated with ostracism, depressive symptoms and social isolation. Conclusions Patients unable to conceal their condition (those with visible physical atypicality and those who changed gender) experienced social stigmatisation. Stigmatisation was stressful and related to isolation and withdrawal from social interaction. Education about DSD, self-empowerment and medical interventions to prevent atypical physical development may remove barriers to acceptance by others for affected individuals.

\section{INTRODUCTION}

Disorders of sex development (DSD) refer to a group of congenital conditions in which development of chromosomal, gonadal or anatomical sex is atypical, often leading to an atypical appearance of the genitals and other parts of the body that differ in appearance between men and women. ${ }^{1}$ Clinicians

\section{What is already known on this topic?}

Disorder of sex development (DSD) is a somatically and socially challenging condition; many patients and parents suffer from emotional problems, experience or anticipate social stigmatisation.

- Opposing opinions rule the debate on how to strengthen patients' emotional well-being and improve their psychosocial opportunities.

- At present DSD-associated social stigma has not been investigated systematically. Such studies are necessary in order to make proper adjustments in clinical management.

\section{What this study hopes to add?}

We developed the Social Stigmatisation Scale for disorder of sex development (DSD) and investigated patients' and parents' experienced stigma.

- Experienced and anticipated DSD-related stigmatisation was highest among patients with body atypicality and patients who changed gender.

- Social stigmatisation was evaluated as stressful, related to (self)isolation and highly correlated with depression.

specialised in DSD treatment are confronted with parents' and patients' difficulties in coping with the atypical physical development and the derogatory reactions their atypicality may elicit. In addition to treatments necessary for survival, clinical management aims to reduce or prevent physical atypicality and to enable sexual functioning in order to increase the patient's opportunities for social participation. These interventions have been criticised, as they impact the child's life and are often performed without the child's assent or consent. It has been argued that such interventions do not allow for diversity in sex and gender development and are principally conducted to comfort parents or support the gender ideology of society. ${ }^{2-6}$ As such, there have been calls to stop this practice of 
medical and surgical intervention. ${ }^{7-9}$ However, there is a lack of systematic data on DSD-associated stigma among affected individuals who did not receive such interventions. ${ }^{2}$ Randomised controlled studies of early gender assignment, genital surgery and hormonal interventions compared with delayed interventions are highly valued ${ }^{10}$ but difficult to conduct. Despite criticisms noted above, most parents living in Western countries choose early gender assignment and surgical correction of the atypical genitalia for their children with DSD. ${ }^{11} 12$ Follow-up studies on quality of life are scarce and findings are inconsistent regarding the risks and benefits of medical intervention. ${ }^{13-15}$ Finally, the medical literature contains few reports on DSD and social stigmatisation. ${ }^{16-23}$

In Indonesia, DSD is not widely known among health practitioners and laymen. Clinical management is challenged by limited diagnostic and treatment facilities. As a result, many patients live with atypical bodies and experience doubts about their gender. ${ }^{24}{ }^{25}$ During outpatient clinic visits, experiences with social stigmatisation were often reported spontaneously by these patients and stimulated many patients and parents to seek medical help. This enabled us to investigate these patients' experiences of living with physical ambiguity and doubts about their gender, ${ }^{24}{ }^{25}$ as well as their experience of social stigmatisation.

\section{METHODS}

\section{Study design and setting}

Experiences with social stigmatisation due to DSD were evaluated from adult patients and parents of affected children and adolescents. Data collection were carried out between March 2007 and May 2011. All patients consulted the DSD Team of the Dr. Kariadi Hospital. The study protocol was approved by the board of the ethical committee at the Faculty of Medicine, Diponegoro University, Semarang, Indonesia.

\section{Patients}

All patients with a confirmed diagnosis of DSD consulting the DSD Team of the Dr. Kariadi Hospital ${ }^{26}$ were invited to participate in the study. Patients and parents received oral and written study information (provided by AZJ). All participating patients and parents provided informed consent. Patients with a genital anomaly and additional features suggestive of a dysmorphic syndrome, ${ }^{27}$ patients with sex chromosome DSD without mosaicism and patients with DSD and intellectual disabilities (indicated from the child's academic achievements and/or observed by the medical doctor in interaction with the patient) were excluded. Thirty-four adults (20 men; 14 women; aged 18-41 years) and 81 parents of 60 children (42 boys, 18 girls; aged $6-11$ ) and 21 adolescents (15 boys; 6 girls; aged $12-17$ years) participated, with a participation rate of $78 \%$. Table 1 summarises patient characteristics and diagnoses.

\section{Procedure}

After obtaining written, informed consent, psychological assessment including data on patients' socioeconomic and ethnic-cultural background ${ }^{142425}$ was collected in the hospital or at the patient's home, by a trained psychologist $(\mathrm{AE})$.

\section{Materials}

Prior to this study, no measure was available to assess social stigmatisation in patients with DSD. Therefore, we developed the Social Stigmatisation Scale for DSD (SSS-DSD). The SSS-DSD assesses the frequency of experienced

Table 1 Disorder of sex development (DSD) diagnoses of participants in the study $(n=115)$

\begin{tabular}{|c|c|c|c|c|c|}
\hline \multirow[b]{2}{*}{ DSD diagnosis } & & \multicolumn{4}{|l|}{ Age } \\
\hline & & $6-11$ & $12-17$ & $18+$ & Total \\
\hline Sex chromosome DSD & $\begin{array}{l}\text { Patients with 45, X/46, XY; } \\
\text { 46, XidicY; 46, XX/46, XY; } \\
\text { 46, XX/47, XXY }\end{array}$ & 6 & 3 & 5 & 14 \\
\hline 46, XY DSD & $\mathrm{AIS}^{*}$ & 5 & 5 & 6 & 16 \\
\hline \multirow[t]{3}{*}{$46, \mathrm{XX} D S D$} & CAH-SV§ & 18 & 2 & 4 & 24 \\
\hline & Gonadal dysgenesis $†$ & - & - & 1 & 1 \\
\hline & Cloacal malformation & - & - & 1 & 1 \\
\hline Total & & 60 & 21 & 34 & 115 \\
\hline
\end{tabular}

${ }^{*}$ Androgen insensitivity syndrome. Androgen receptor gene mutation was confirmed. ${ }^{26}$

†Abnormal hormonal testicular function with unilaterally/bilaterally undescended testes. The clinical and biochemical presentation suggest gonadal dysfunction. Serum levels of luteinising hormone and follicle stimulating hormone were elevated but testosterone, anti-Müllerian hormone and inhibin are low for age, and no or diminished serum testosterone response to human chorionic gonadotropin.

$\ddagger 46, X Y$ karyotype with hypomasculinisation of unknown cause, despite extensive analysis. ${ }^{26}$

§Congenital adrenal hyperplasia simple virilising type. CYP 21 mutation was confirmed. ${ }^{26}$

Details on diagnosis and degree of masculinisation at admission per patient can be found in Ediati et al. ${ }^{1424}$ 
stigmatisation (1-13a questions) and the level of stress evoked by the stigmatising experiences (1-13b questions) using a Likert scale with responses ranging from 'not at all' 1 to 'very much'. ${ }^{5}$ In addition, we asked patients to give details about their experiences with DSD, their beliefs on the cause of their DSD, their concerns and ability to cope with DSD (1-12c questions). We developed parent and adult versions of the SSS-DSD.

The applicability of the SSS-DSD was tested (by AE) prior to implementation and revealed that applying the measure as a paper-pencil test was feasible for well-educated subjects. The rating scale was piloted in a small group of 20 patients and parents with DSD. After a few adaptations, the SSS-DSD seemed suitable for application in this study. Formal large scale psychometric pretesting among sizeable numbers of patients or their parents was considered unfeasible in view of the limited numbers of patients with rare genetic conditions. For parents and patients who could not read well, the measure was applied verbally.

\section{Data analysis}

Construct validity of both the adult and parental versions of the SSS-DSD scale was explored using principal component analysis (PCA) with varimax rotation and Kaiser normalisation method. Factors with eigenvalues greater than 1 and items with factor loadings (after rotation) greater than 0.40 were considered acceptable. The reliability of the instrument was evaluated using Cronbach's $\alpha$ as a measure of internal consistency.

The overall and domain sum scores of the SSS-DSD were calculated as the unweighted sum scores of the individual domains and items, respectively. For all sum scores, a higher score indicates a relatively higher level of stigma, atypicality, social exclusion and emotional problems. With Spearman's correlation coefficient $(r)$ the correlations between different types of stigma and evoked stress were evaluated. The Kruskal-Wallis test was applied to test for differences in continuous data of more than two groups, the Mann-Whitney $\mathrm{U}$ test for differences between two independent groups. Differences in categorical data were compared using Fisher's exact test. Differences were considered significant at $\mathrm{p}<0.05$ (two-sided).

Qualitative data collected were analysed by inductive content analyses using NVivo qualitative data analysis software. ${ }^{28}{ }^{29} \mathrm{AE}$ started an open coding procedure and finally clustered codes into four themes. Relationships between themes were investigated using the compound coding application in NVivo. ${ }^{28} 29$

\section{RESULTS}

The majority of participants were men, lived in rural areas, Javanese and Muslim. Parents' educational backgrounds varied from no formal education to university level, and the majority attended high school and worked in the lower-income sector or were unemployed. Details on socioeconomic and ethnic-cultural variables can be found in table 2 .

Reliability and validity of SSS-DSD parent and adult versions SSS-DSD parent

The PCA extracted four components with Cronbach's $\alpha$ ranging between 0.84 and 0.88 . Reliability (internal consistency) of the parent version can be considered as good. The four components explaining $56 \%$ of the total variance were as follows: (1) stigmatisation elicited by genital ambiguity (items $1-2,5-6,11 ; \alpha=0.86$ ); (2) stigmatisation elicited by atypical physical appearance or cross-gender role behaviour (items 3-4, 7-8a; $\alpha=0.84$ ); (3) social exclusion (items 9-10, 12; $\alpha=0.88$ ) and (4) emotional problems due to DSD (items 13a-d, 13g-h; $\alpha=0.85$ ). Table $3 \mathrm{~A}$ shows the factor loadings after varimax rotation and the Cronbach's $\alpha$ of each component. The construct validity of the SSS-DSD parent was considered satisfactory.

\section{SSS-DSD adult}

The PCA extracted three components with Cronbach's $\alpha$ ranging between 0.85 and 0.94 . Reliability (internal consistency) of the Adult version was considered as good to very good. The extracted three components explaining $62.9 \%$ of the total variance were as follows: (1)verbal stigmatisation (items $1-2,4-5,7$; $\alpha=0.92$ ); (2) behavioural stigmatisation (items $3,6 \mathrm{a}, 9-10 ; \alpha=0.85$ ) and (3) emotional problems due to DSD (items 13-15; $\alpha=0.94$ ). Table $3 \mathrm{~B}$ shows the factor loadings after varimax rotation and the Cronbach's $\alpha$ of each component. The construct validity of the SSS-DSD adult was also considered satisfactory.

\section{Correlations between stigmatisation and stress}

In both measures, items measuring experiences with stigmatisation were positively and significantly correlated with items measuring stress evoked by such stigmatisation, in all components measured.

\section{SSS-DSD parent}

Stigmatisation due to genital ambiguity positively correlated with stress $\left(\mathrm{r}_{\mathrm{s}}(79)=0.794, \mathrm{p}<0.001\right)$; stigmatisation elicited by an ambiguous appearance or behaviour positively correlated with stress $\left(\mathrm{r}_{\mathrm{s}}(79)=0.80, \mathrm{p}<0.001\right)$; social rejection positively correlated with stress $\left(\mathrm{r}_{\mathrm{s}}(79)=0.81\right.$, $\mathrm{p}<0.001)$ and emotional problems also positively correlated with stress $\left(\mathrm{r}_{\mathrm{s}}(79)=0.64, \mathrm{p}<0.001\right)$.

\section{SSS-DSD adult}

Verbal stigmatisation positively correlated with stress $\left(\mathrm{r}_{\mathrm{s}}(32)=0.755, \mathrm{p}<0.001\right)$; behavioural stigmatisation positively correlated with stress $\left(\mathrm{r}_{\mathrm{s}}(32)=0.753, \mathrm{p}<0.001\right)$ and emotional and acceptance problems due to DSD also positively correlated with stress $\left(\mathrm{r}_{\mathrm{s}}(32)=0.882, \mathrm{p}<0.001\right)$. The more frequently patients experienced social stigmatisation, the higher their reported stress. 
Table 2 Participant characteristics $(\mathrm{N}=115)$

\begin{tabular}{|c|c|c|}
\hline Characteristics & $\begin{array}{l}\text { Children and } \\
\text { adolescents }(n=81)\end{array}$ & $\begin{array}{l}\text { Adults } \\
(n=34)\end{array}$ \\
\hline \multicolumn{3}{|l|}{ Gender (of patients) } \\
\hline Male & $57(70)$ & $20(59)$ \\
\hline Female & $24(30)$ & $14(41)$ \\
\hline \multicolumn{3}{|l|}{ Treatment } \\
\hline Received treatment ${ }^{\star}$ & $44(54)$ & $15(44)$ \\
\hline No treatment & $37(46)$ & $19(56)$ \\
\hline \multicolumn{3}{|l|}{ Social gender role change $†$} \\
\hline Yes & $7(9)$ & $15(44)$ \\
\hline No & 74 (91) & $19(56)$ \\
\hline \multicolumn{3}{|l|}{ Visibility of DSD $\ddagger$} \\
\hline Visible & $12(15)$ & $17(50)$ \\
\hline Partly hidden & $57(70)$ & $17(50)$ \\
\hline Hidden & $12(15)$ & \\
\hline \multicolumn{3}{|l|}{ Region } \\
\hline Central Java & $70(86)$ & $29(85)$ \\
\hline Other provinces in Java & $8(10)$ & $2(6)$ \\
\hline Outside Java island & $3(4)$ & $3(9)$ \\
\hline \multicolumn{3}{|l|}{ Ethnic } \\
\hline Javanese & $76(94)$ & $31(91)$ \\
\hline Non-Javanese & $5(6)$ & $3(9)$ \\
\hline \multicolumn{3}{|l|}{ Religion } \\
\hline Islam & 77 (95) & $33(97)$ \\
\hline Non-Islam & $4(5)$ & $1(3)$ \\
\hline \multicolumn{3}{|l|}{ Residential setting } \\
\hline Rural & $45(56)$ & $15(44)$ \\
\hline Suburban & $24(30)$ & $11(32)$ \\
\hline Urban & $12(15)$ & $8(24)$ \\
\hline Highest education attained & (Fathers§ / mothers§) & (Adults) \\
\hline No formal education & 9 (11) / 10 (13) & $4(12)$ \\
\hline Elementary school & 27 (34) / 28 (35) & $3(9)$ \\
\hline High school & $36(45)$ / 36 (45) & $23(68)$ \\
\hline University & 8 (10) / 6 (8) & $4(12)$ \\
\hline Parents' occupation & (Fathers / mothers§) & (Adults) \\
\hline Unemployed & $0 / 44$ (55) & $13(38)$ \\
\hline Labour & $47(59)$ / $22(28)$ & $9(27)$ \\
\hline Self-employed & $16(20) / 6(8)$ & $4(12)$ \\
\hline Staff & 17 (21) /8 (10) & $8(24)$ \\
\hline
\end{tabular}

Data are presented in $\mathrm{n}(\%)$.

*Treatment in most patients had been minimal, for instance, patients had taken glucocorticoid therapy for only a limited period or had undergone one surgical procedure for hypospadias correction when two or more procedures were recommended. ${ }^{1425-27}$

†Social gender role change could be physician imposed, parent imposed or patient initiated. ${ }^{25}$

$\neq$ Visibility of DSD refer to all those aspects of physical and behavioural atypicality that cannot be hidden during social interaction. Concealable refers to physical atypicality that can be covered by clothes (partly hidden) and non-ambiguous phenotype (hidden).

§One father / mother missing for being deceased.

DSD, disorder of sex development.

\section{Subgroup analysis}

Tables 4A and B summarise the comparisons across sex of rearing, treatment status, gender change history ${ }^{24}$ and visibility of DSD conditions. In both boys and girls, children and adolescents experienced some degree of stigmatisation. Girls reported more stigmatisation due to atypical physical appearance or cross-gender role behaviour and had more emotional problems than boys (see table 4A; gender comparison). Women experienced more stigmatisation and had more emotional problems than men. Both men and women experienced some degree of verbal and behavioural reactions due to their DSD conditions (see table 4B; gender comparison).

Regardless of having received prior hormonal/surgical treatment for DSD, children and adolescents experienced stigmatisation and had emotional problems (see table 4A; treatment status comparison). However, untreated adults experienced more stigmatisation than treated adults (see table 4B; treatment status comparison).

Six youngsters and 15 adults were assigned female at birth but changed gender later in life. ${ }^{24}$ These patients experienced more stigmatisation than patients who kept their initial gender. Young people and adults experienced more stigmatisation due to an ambiguous appearance or cross-gender behaviour and had more emotional problems than youngsters who retained the initial sex of rearing (see tables $4 \mathrm{~A}$ and $\mathrm{B}$; social gender role change comparison). Adults who changed gender experienced more behavioural stigmatisation than adults who retained the gender assigned at birth (see table 4B; gender change history comparison).

Children and adolescents with visible ambiguity of the body experienced stigmatisation more frequently than patients who could conceal ambiguous characteristics (see table 4A; visibility of DSD comparison). Regardless of the visibility of DSD, children and adolescents reported emotional problems due to DSD. Adults with visible ambiguity of the body experienced more stigmatisation than adults who could conceal ambiguity; this was particularly seen in verbal and behavioural stigmatisation (see table 4B; visibility of DSD comparison).

\section{Qualitative data}

In text analyses, four themes were identified that gave insight into characteristics of social stigmatisation and related stress: (1) (correct, incorrect or lack of) knowledge about DSD, (2) patients' personality and related emotional and behavioural responses, (3) cultural norms and related social expectancies and (4) response from the community.

\section{DISCUSSION}

Our study revealed that atypical appearance of the genitals and/or body is problematic. ${ }^{14}$ Stigmatisation was most prominent in patients with an atypical physical appearance who could not hide their ambiguity, in untreated adult patients, in patients who changed their social gender 
Table 3 Factor loadings after varimax rotation and Cronbach's $\alpha$ of the SSS-DSD:

(A) Parental report $(\mathrm{n}=81)$

\begin{tabular}{|c|c|c|c|c|}
\hline \multirow[b]{2}{*}{ Questions } & \multicolumn{4}{|c|}{ Components } \\
\hline & $1^{*}$ & $2 \dagger$ & $3 \ddagger$ & $4 \S$ \\
\hline \multicolumn{5}{|l|}{ Stigma elicited by genital atypicality* } \\
\hline $\begin{array}{l}\text { 01a. Can other people see that your child has genitals that are (slightly) different } \\
\text { from that of other children? }\end{array}$ & 0.60 & 0.44 & 0.07 & -0.14 \\
\hline $01 \mathrm{~b}$. How stressful is this to you? & 0.72 & 0.22 & 0.31 & -0.09 \\
\hline \multicolumn{5}{|l|}{ 01cף. Open-ended question: Can you tell us more about this? } \\
\hline $\begin{array}{l}\text { 02a. Do you think that other people look at your child because of their atypical } \\
\text { genitalia? }\end{array}$ & 0.64 & 0.38 & -0.05 & 0.19 \\
\hline 02b. How stressful is this to you? & 0.73 & 0.13 & 0.17 & 0.21 \\
\hline $\begin{array}{l}\text { 05a. Do other people speak negatively about your child because of their atypical } \\
\text { genital or physical appearance? }\end{array}$ & 0.65 & -0.05 & 0.27 & 0.24 \\
\hline 05b. How stressful is this to you? & 0.67 & -0.10 & 0.34 & 0.14 \\
\hline 06a. Do people speak negatively about you because of your child? & 0.76 & -0.07 & -0.18 & 0.13 \\
\hline 06b. How stressful is this to you? & 0.73 & -0.11 & -0.17 & 0.15 \\
\hline $\begin{array}{l}\text { 11a. Is your child called names or teased by other children because of their atypical } \\
\text { genital or physical appearance? }\end{array}$ & 0.40 & 0.03 & 0.24 & 0.55 \\
\hline 11b. How stressful is this to you? & 0.41 & 0.02 & 0.44 & 0.49 \\
\hline \multicolumn{5}{|l|}{ Stigma elicited by physical atypicality or cross gender role behaviour $\dagger$} \\
\hline 03a. Can other people see that your child has an atypical physical appearance? & -0.09 & 0.76 & 0.07 & 0.35 \\
\hline 03b. How stressful is this to you? & -0.14 & 0.52 & 0.18 & 0.48 \\
\hline $\begin{array}{l}\text { 04a. Do you think that other people look at your child because of their atypical } \\
\text { physical appearance? }\end{array}$ & 0.39 & 0.67 & -0.21 & 0.16 \\
\hline 04b. How stressful is this to you? & 0.17 & 0.57 & 0.13 & -0.01 \\
\hline $\begin{array}{l}\text { 07a. Does your child show more cross-gender role behaviour compared with other } \\
\text { children? For parents of daughters: Does your daughter prefer more masculine } \\
\text { activities than other girls? For parents of sons: Does your son prefer more feminine } \\
\text { activities compared with other boys? }\end{array}$ & -0.06 & 0.87 & 0.10 & 0.20 \\
\hline 07b. How stressful is this to you? & -0.01 & 0.91 & 0.04 & 0.02 \\
\hline $\begin{array}{l}\text { 08a. Do other people speak or behave negatively about your child because of their } \\
\text { cross-gender role behaviour? (Daughters: masculine behaviour and interests? Sons: } \\
\text { feminine behaviour and interests?) }\end{array}$ & 0.11 & 0.44 & -0.08 & -0.05 \\
\hline \multicolumn{5}{|l|}{ Experiences with social exclusion $\ddagger$} \\
\hline $\begin{array}{l}\text { 09a. Do other people isolate your child because of atypical of their genital/physical } \\
\text { appearance? }\end{array}$ & -0.03 & 0.34 & 0.76 & 0.19 \\
\hline 09b. How stressful is this to you? & 0.04 & 0.24 & 0.85 & 0.03 \\
\hline 10a. Do other people isolate you because of your child? & 0.17 & -0.10 & 0.86 & -0.13 \\
\hline $10 \mathrm{~b}$. How stressful is this to you? & 0.21 & -0.12 & 0.82 & -0.14 \\
\hline $\begin{array}{l}\text { 12a. Is your child isolated by other children because of their atypical genital or } \\
\text { physical appearance? }\end{array}$ & -0.09 & 0.00 & 0.75 & 0.45 \\
\hline $12 \mathrm{~b}$. How stressful is this to you? & 0.02 & -0.08 & 0.88 & 0.22 \\
\hline \multicolumn{5}{|l|}{ Emotional reactions§ } \\
\hline $\begin{array}{l}\text { 13a. Does your child suffer from emotional problems because of their atypical } \\
\text { genital or physical appearance? }\end{array}$ & 0.26 & 0.00 & -0.07 & 0.75 \\
\hline $13 \mathrm{~b}$. How stressful is this to you? & 0.13 & 0.02 & -0.03 & 0.82 \\
\hline 13c. How frequent was your child sad? & 0.09 & 0.06 & -0.05 & 0.55 \\
\hline 13d. How frequent was your child depressed? & 0.01 & -0.01 & 0.07 & 0.82 \\
\hline 13g. How frequent was your child shy? & -0.14 & 0.14 & 0.13 & 0.71 \\
\hline
\end{tabular}


Table 3 Continued

(A) Parental report $(\mathrm{n}=\mathbf{8 1})$

\begin{tabular}{|c|c|c|c|c|}
\hline \multirow[b]{2}{*}{ Questions } & \multicolumn{4}{|c|}{ Components } \\
\hline & $1^{*}$ & $2 \dagger$ & $3 \ddagger$ & $4 \S$ \\
\hline 13h. How frequent was your child socially withdrawn? & -0.11 & 0.34 & 0.13 & 0.61 \\
\hline 13e. How frequent was your child angry? & 0.01 & 0.19 & 0.20 & 0.37 \\
\hline 13f. How frequent was your child aggressive? & 0.12 & 0.05 & 0.28 & 0.24 \\
\hline 14. Are you worried about your child's future? & 0.20 & -0.01 & 0.05 & 0.29 \\
\hline 15. Is it difficult for you to accept your child? & 0.25 & 0.07 & 0.02 & -0.12 \\
\hline
\end{tabular}

*Stigmatisation due to genital ambiguity and stress evoked by such experiences $(\alpha=0.86)$.

†Stigmatisation due to atypical physical appearance or displayed cross-gender role behaviour and stress evoked by such experiences $(\alpha=0.84)$.

¥Social exclusion or isolation due to DSD and stress evoked by being rejected or isolated $(\alpha=0.88)$.

$\S$ Reported emotional problems seen in the child and parental stress evoked these emotional problems $(\alpha=0.85)$.

IEach question 1-12 was followed by an open-ended question: Can you tell us more about this? Example?

SSS-DSD, Social Stigmatisation Scale-disorder of sex development.

and in girls and women. The more frequently they experienced DSD-related social stigma, the higher their stress. Patients who were able to hide features of body atypicality from others did not report less emotional problems than patients who had visible features of DSD. This suggests that fear and prevention of being stigmatised is as problematic as having experienced stigmatisation. From the qualitative data, we observed that a substantial number of patients withdrew themselves from social interactions, such as withdrawal from school and avoiding interaction with neighbours or community members. In Indonesia, those who show variant sex or gender development are often met with a hostile attitude; patients are humiliated and excluded.

Overall, many patients did not give high rates of experienced social stigmatisation; however, patients with atypical physical appearance are vulnerable to social stigmatisation. They indicated that stigmatisation was stressful, elicited negative emotions, hampered social participation and hence affected overall psychosocial well-being. Part of their social stigmatisation was related to lack of knowledge about DSD among patients themselves and among Indonesian laymen. We propose that stigmatisation can be prevented or reduced by education. Similar to many other non-western countries, Indonesia has few well-trained medical psychologists available for counselling to help patients and parents cope with DSD. Once educated and supported, patients and parents can then educate their social network to improve their position in the community. ${ }^{30}$ In addition, educated patients and parents will be better able to decide which treatments are optimal for their particular circumstances.

Indonesia is a collective society in which procreation and progeny are highly valued. Some people with DSD cannot meet such expectations. ${ }^{142425}$ Our findings are in line with previous studies reporting sexual distress, disclosure dilemmas and tendency to avoid romantic relationships among women with DSD. ${ }^{25}$ Women with
DSD report a more vulnerable position than affected men in this culture. This may explain why we recruited more male patients $(59 \%)$ than female patients $(41 \%)$ for this study. This study includes 20 patients who underwent a female to male social gender change, 4 patients changed gender in childhood, 16 of them initiated a change in adolescence or adulthood. Three patients had a 46, XX karyotype and CAH, 17 patients had a 46 , XY karyotype. ${ }^{24}$

Progressive masculinisation may have induced gender dysphoria and instigated the wish to change gender, but ostracism may also contribute to this change.

Limited assessment of the construct validity of the SSS-DSD is a study limitation. Our study focused on the relationship between social stigmatisation and atypical appearance resulting from the delay of medical and surgical treatment. As no suitable measure was available, we developed one. In developing a measure, it is preferred to perform cross-validation studies in addition to PCA to assess construct validity more extensively. Unfortunately, quantitative measures to assess different aspects of psychosocial well-being are unavailable in Indonesia and we were unable to perform such analyses. ${ }^{142425}$

This study is relevant for patients with DSD who face delay in treatment due to poor understanding of their medical condition, inadequate laboratory support and lack of appropriate and affordable medications. ${ }^{21}$ Although Western culture is individual centered and the demands to follow social norms (e.g., giving birth for women) are less stringent, Western patients with DSD have a vulnerable position in society too. Thus, the current results may be informative to patients and families outside of Indonesia. Ultimately, we aim to optimise patients' psychosexual and psychosocial well-being and are searching for adaptations in clinical management that are evidence-based, such as the reduction of stigmatisation of those affected by DSD. ${ }^{13}$ 
Table 3

(B) Adult report $(\mathrm{n}=34)$

\begin{tabular}{|c|c|c|c|}
\hline \multirow[b]{2}{*}{ Questions } & \multicolumn{3}{|c|}{ Components } \\
\hline & $1^{*}$ & $2 \dagger$ & $3 \ddagger$ \\
\hline \multicolumn{4}{|l|}{ Verbal stigmatisation* } \\
\hline $\begin{array}{l}\text { 1a. Can other people see that you have genitalia that are (slightly) different from other men/ } \\
\text { women? }\end{array}$ & 0.63 & 0.03 & 0.10 \\
\hline 1b. How stressful is this to you? & 0.62 & 0.36 & 0.42 \\
\hline \multicolumn{4}{|l|}{ 1c§. Open-ended question: Can you tell us more about this? } \\
\hline 2a. Do you think that other people look at you because of your atypical genitalia? & 0.79 & 0.33 & 0.22 \\
\hline $2 \mathrm{~b}$. How stressful is this to you? & 0.86 & 0.19 & 0.23 \\
\hline 4a. Do you think that other people look at you because of your atypical physical appearance? & 0.71 & -0.08 & 0.37 \\
\hline $4 \mathrm{~b}$. How stressful is this to you? & 0.82 & 0.21 & 0.25 \\
\hline $\begin{array}{l}\text { 5a. Do other people speak negatively about you because of your atypical genital or physical } \\
\text { appearance? }\end{array}$ & 0.75 & 0.08 & -0.13 \\
\hline 5b. How stressful is this to you? & 0.86 & 0.10 & -0.05 \\
\hline \multicolumn{4}{|l|}{$\begin{array}{l}\text { 7a. Do other people, including family members, speak or behave negatively about you because } \\
\text { you show more cross-gender behaviour compared with others? }\end{array}$} \\
\hline $\begin{array}{l}\text { (For woman: Do you prefer more masculine activities compared with other women? } \\
\text { For man: do you prefer more feminine activities compared with other men?) }\end{array}$ & 0.73 & -0.27 & 0.12 \\
\hline 7b. How stressful is this to you? & 0.71 & -0.23 & 0.12 \\
\hline \multicolumn{4}{|l|}{ Behavioural stigmatisation $†$} \\
\hline 3a. Can other people see that you have an atypical appearance? & 0.08 & 0.65 & 0.41 \\
\hline 3b. How stressful is this to you? & 0.43 & 0.55 & 0.23 \\
\hline 6a. Do you behave (slightly) differently from other men/women? & 0.01 & 0.64 & 0.17 \\
\hline 6b. How stressful is this to you? & 0.16 & 0.36 & 0.10 \\
\hline $\begin{array}{l}\text { 9a. Do other people tease you or call you by funny names because of your atypical genital or } \\
\text { physical appearance? }\end{array}$ & 0.10 & 0.84 & 0.07 \\
\hline 9b. How stressful is this to you? & 0.15 & 0.87 & 0.18 \\
\hline $\begin{array}{l}\text { 10a. Do other people isolate/reject you because of your atypical genital or physical } \\
\text { appearance? }\end{array}$ & -0.21 & 0.68 & 0.23 \\
\hline $10 \mathrm{~b}$. How stressful is this to you? & -0.21 & 0.68 & 0.23 \\
\hline \multicolumn{4}{|l|}{ Emotional problems } \\
\hline 13a. Do you suffer from emotional problems because of your atypical genital/appearance? & 0.31 & 0.40 & 0.75 \\
\hline 13b. How stressful is this to you? & 0.31 & 0.37 & 0.75 \\
\hline 13c. How frequently were you sad? & -0.06 & 0.20 & 0.94 \\
\hline 13d. How frequently were you depressed? & 0.11 & 0.16 & 0.93 \\
\hline 13e. How frequently were you angry? & 0.34 & 0.31 & 0.68 \\
\hline 13g. How frequently were you shy? & 0.17 & 0.16 & 0.73 \\
\hline 13h. How frequently were you socially withdrawn? & 0.11 & 0.14 & 0.71 \\
\hline 14. Are you worried about your future? & 0.21 & 0.10 & 0.74 \\
\hline 15. Is it difficult for you to accept your condition? & -0.02 & 0.20 & 0.75 \\
\hline
\end{tabular}

*Verbal reaction received due to DSD conditions and the stress evoked by such experiences $(\alpha=0.92)$.

†Behavioural reaction received due to DSD conditions and the stress evoked by such experiences $(\alpha=0.85)$.

$\ddagger$ Reported emotional problem due to having DSD conditions $(\alpha=0.94)$.

§Each question 1-7, 9, 10 was followed by an open-ended question: Can you tell us more about this? Example?

SSS-DSD, Social Stigmatisation Scale-disorder of sex development.

\section{CONCLUSION}

Patients with DSD, particularly those with an atypical appearance, are prone to stigmatisation. Such stigmatisation is stressful and leads to negative emotional reactions and social isolation. These findings support the assumption that an atypical physical appearance can be 


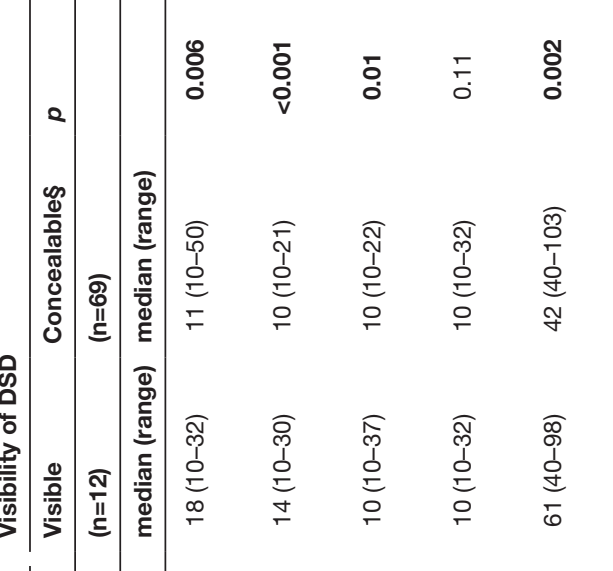

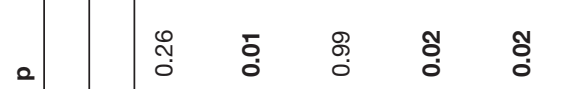

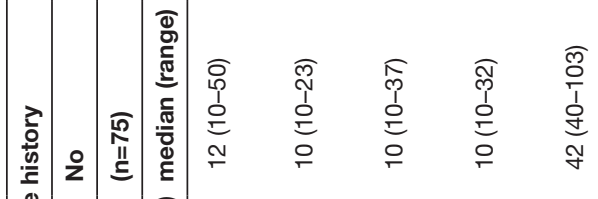

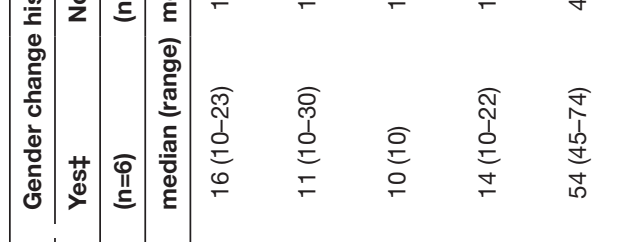

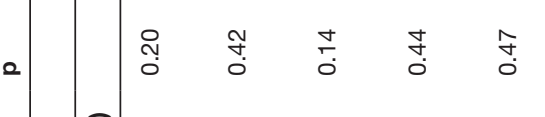

ฐ

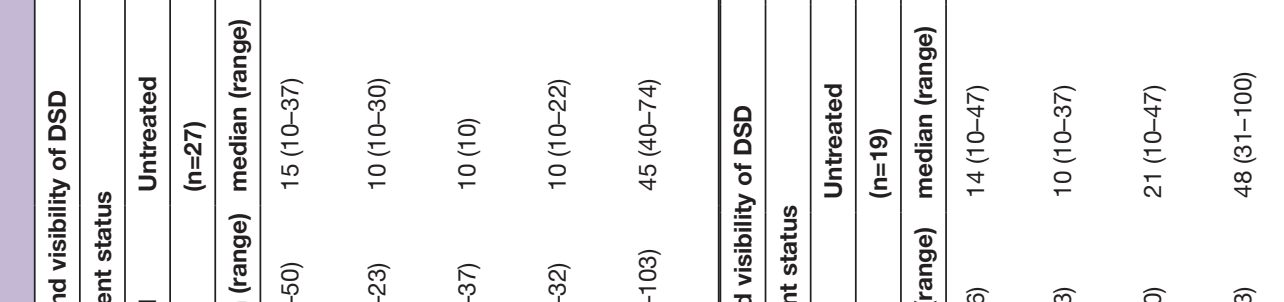

항.

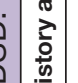

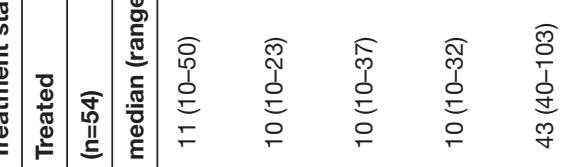

竞:

โ)

:

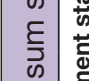

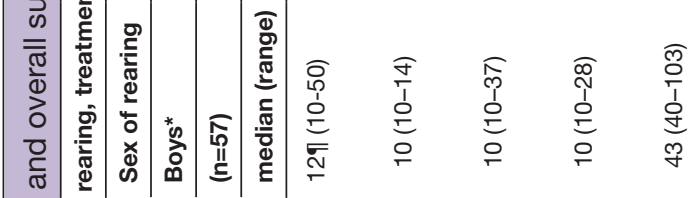

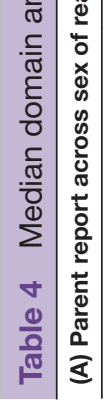

ฮ

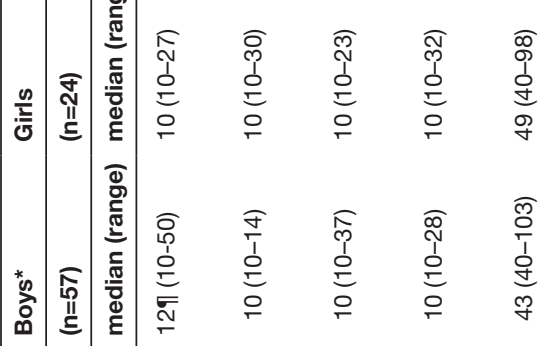

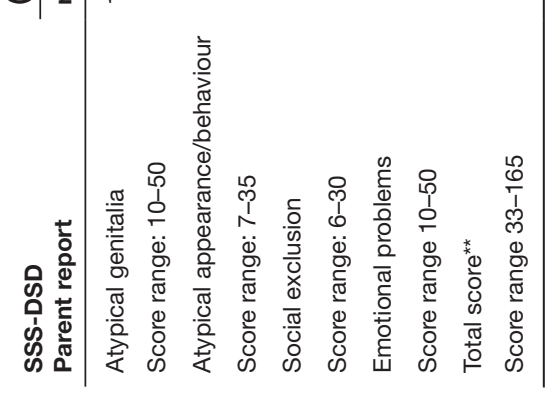

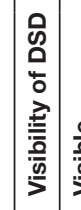

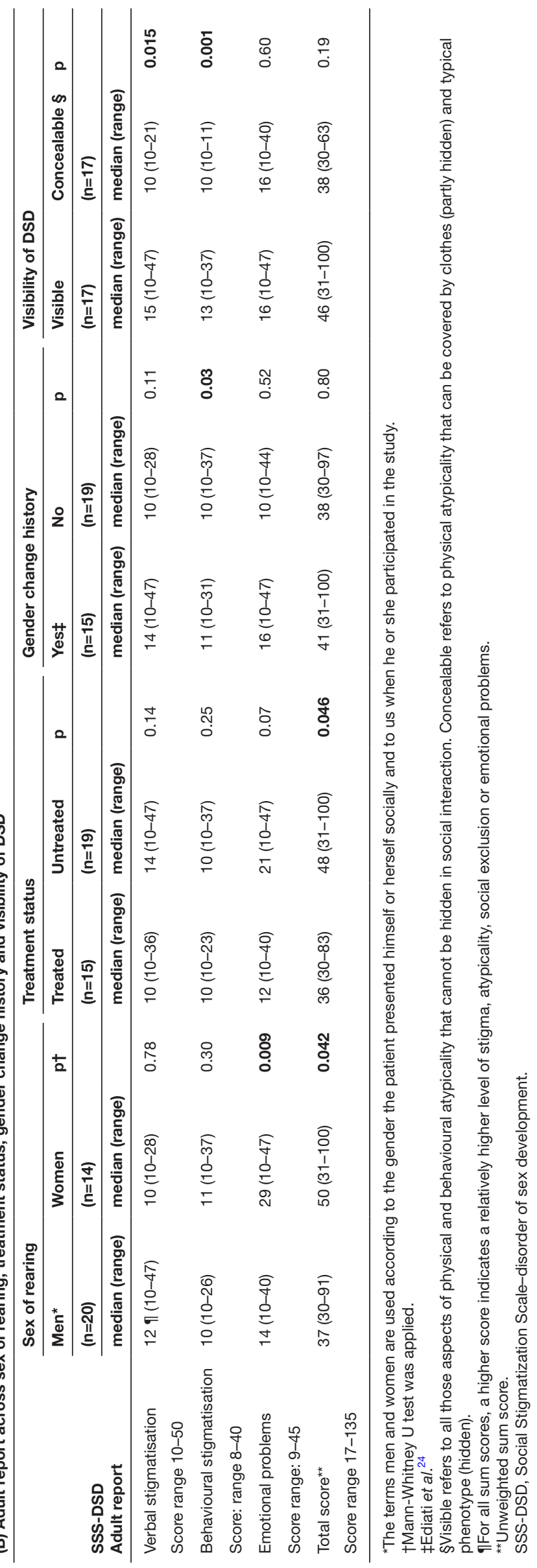

$\frac{0}{3}$

$\overrightarrow{\mathrm{F}}$

흘.

$\therefore$

$\overrightarrow{0}$

$\vec{\omega}$

능.

กิ

ठे

$\vec{\omega}$



○

$\underset{\square}{\circ}$

옥

8

흥

$\frac{8}{2}$

윽

吾

흠.

을.

N

N

$\stackrel{0}{\mathbb{D}}$ 
harmful for psychosocial well-being. This may be particularly true when the medical condition is not understood by the patient, the parents and members of the community, as well as when the patient cannot make their own decisions regarding clinical management. Culturally sensitive education about DSD that is accessible to patients, families and the community would go a long way towards improving social acceptance and thereby the well-being of (young) people with DSD.

Acknowledgements The authors thank all the participants in the study for their willingness to be interviewed and disclose the struggle with social stigmatisation in daily life. We thank Dr Saskia E Wieringa, from the University of Amsterdam, Department of Sociology and Anthropology, for advice during the preparation of the Indonesian measures used in this study. We thank Dr Anne de la Croix, from the Free University Amsterdam, Faculty of Behavioural and Movement Sciences, for advice and help in analysing the qualitative data. We thank Dr Jillian Bryce, from University of Glasgow, School of Medicine, for editorial help.

Contributors SMHF and SD initiated the study. SMHF, SD and AW had been involved in written revisions of the manuscript. $A E, A D$ and $E B$ designed the study, analysed the data, produced the figures and performed literature searches and written revisions. $\mathrm{AE}, \mathrm{JO}$ and $\mathrm{AD}$ developed the questionnaires, $\mathrm{AE}$ collected the data.

Funding AE and AZJ were supported by a DIKTI scholarship from the Directorate of Higher Education, Ministry of National Education and Culture, the Republic of Indonesia.

Competing interests None declared.

Patient consent Obtained.

Ethics approval Ethical Committee at the Faculty of Medicine, Diponegoro University, Semarang, Indonesia

Provenance and peer review Not commissioned; externally peer reviewed.

Open Access This is an Open Access article distributed in accordance with the Creative Commons Attribution Non Commercial (CC BY-NC 4.0) license, which permits others to distribute, remix, adapt, build upon this work non-commercially, and license their derivative works on different terms, provided the original work is properly cited and the use is non-commercial. See: http://creativecommons.org/ licenses/by-nc/4.0/

(C) Article author(s) (or their employer(s) unless otherwise stated in the text of the article) 2017. All rights reserved. No commercial use is permitted unless otherwise expressly granted.

\section{REFERENCES}

1. Hughes IA, Houk C, Ahmed SF, et al. Consensus statement on management of intersex disorders. J Pediatr Urol 2006;2:148-62.

2. Meyer-Bahlburg HF, Reyes-Portillo JA, Khuri J, et al. Syndromerelated stigma in the general social environment as reported by women with classical congenital adrenal hyperplasia. Arch Sex Behav 2017;46:341-51.

3. Fausto-Sterling A. Sexing the body: Gender politics and the construction of sexuality. New York: Basic Books, 2000.

4. Dreger AD. "Ambiguous sex"--or ambivalent medicine? Ethica issues in the treatment of intersexuality. Hastings Cent Rep 1998:28:24-35.

5. Chase C. Hermaphrodites with an attitude. Mapping the emergence of intersex political activism. GLQ: A Journal of Lesbian and Gay Studies 1998;4:189-211.

6. Chase C. Rethinking treatment for ambiguous genitalia. Pediatr Nurs 1999;25:451-5.
7. Senate Community Affairs Reference Committee. Involuntary or coerced sterilisation of intersex people in Australia, 2013.

8. Human rights and intersex people. Council of Europe, commissioner for human rights. http://www.coe.int/fi/web/commissioner/-/europedisregards-intersex-people-s-right-to-self-determination-andphysical-integrity.

9. Cools M, Simmonds M, Elford S, et al. Response to the council of Europe human rights commissioner's issue paper on human rights and intersex people. Eur Urol 2016;70:407-9.

10. NICHD Workshop. Growing up with DSD: critical developmental issues for children and families affected by DSD. Bethesda, MD, 2014.

11. Sanders C, Carter B, Goodacre L. Parents' narratives about their experiences of their child's reconstructive genital surgeries for ambiguous genitalia. J Clin Nurs 2008;17:3187-95.

12. Crissman HP, Warner L, Gardner M, et al. Children with disorders of sex development: A qualitative study of early parental experience. Int J Pediatr Endocrinol 2011;2011:10.

13. Nordenström A. Psychosocial factors in disorders of sex development in a long term perspective: what clinical opportunities are there to intervene? Horm Metab Res 2015;47:351-6.

14. Ediati A, Faradz SM, Juniarto AZ, et al. Emotional and behavioral problems in late-identified Indonesian patients with disorders of sex development. J Psychosom Res 2015;79:76-84.

15. de Neve-Enthoven NG, Callens N, van Kuyk M, et al. Psychosocial well-being in Dutch adults with disorders of sex development. $J$ Psychosom Res 2016;83:57-64

16. Rolston AM, Gardner M, Vilain E, et al. Parental reports of stigma associated with child's disorder of sex development (DSD). Int $J$ Endocrinol 2015;2015:1-15.

17. Kuhnle U, Krahl W. The impact of culture on sex assignment and gender development in intersex patients. Perspect Biol Med 2002;45:85-103.

18. Armstrong KL, Henderson C, Hoan NT, et al. Living with congenital adrenal hyperplasia in Vietnam: a survey of parents. $J$ Pediatr Endocrinol Metab 2006;19:1207-23.

19. Warne GL, Raza J. Disorders of sex development (DSDs), their presentation and management in different cultures. Rev Endocr Metab Disord 2008;9:227-36.

20. Warne G, Bhatia V. Intersex, East and West. Sytsma SE, ed. Ethics and intersex. Netherlands: Springer, 2006:183-205.

21. Zainuddin AA, Grover SR, Shamsuddin K, et al. Research on quality of life in female patients with congenital adrenal hyperplasia and issues in developing nations. J Pediatr Adolesc Gynecol 2013;26:296-304.

22. Joseph AA, Kulshreshtha B, Shabir I, et al. Gender issues and related social stigma affecting patients with a disorder of sex development in India. Arch Sex Behav 2017;46:361-7.

23. Mazen IA. Clinical management of gender in Egypt: intersexuality and transsexualism. Arch Sex Behav 2017;46:369-72.

24. Ediati A, Juniarto AZ, Birnie E, et al. Gender development in Indonesian children, adolescents, and adults with disorders of sex development. Arch Sex Behav 2015;44:1339-61.

25. Ediati A, Juniarto AZ, Birnie E, et al. Body image and sexuality in Indonesian adults with a disorder of sex development (DSD). J Sex Res 2015;52:15-29.

26. Juniarto $A Z$, van der Zwan $Y G$, Santosa $A$, et al. Hormonal evaluation in relation to phenotype and genotype in 286 patients with a disorder of sex development from Indonesia. Clin Endocrinol 2016:85:247-57.

27. Hutson JM, Grover SR, O'Connell M, et al. Malformation syndromes associated with disorders of sex development. Nat Rev Endocrinol 2014:10:476-87.

28. QSR International. NVivo qualitative data analysis software. 10, 2012 QSR International Pty Ltd, 2012.

29. QSR International. NVIVO 10 for Windows: Getting started: QSR International Pty Ltd, 2013.

30. Johnston S, Irving H, Mill K, et al. The patient's voice: an exploratory study of the impact of a group self-management support program. BMC Fam Pract 2012;13:65. 